\title{
Writing a Case Report: A Work of Art
}

\author{
Christian Ortega-Loubon,' Ricardo Correa-Márquez. ${ }^{2}$
}

Case reports are a time-honored, important, integral, accepted work, firmly established within the medical literature, and represent a growing importance of valuable clinical medical information.' Parkinson's disease, and Kaposi's Sarcoma are only two examples of famous diseases first described in the case report format, making us acknowledge the value of case reports to the scientific literature. Case reports are valuable resources of new and unusual information that may lead to vital research and advances in clinical practice that improve patient outcomes.

Despite the fact that it lies at the bottom of the evidence based classification, the value and contribution of case reports to the advancement of medicine is huge. This will continue in the future. There are 190.703 citations with the term of "case report" up until November 2012 in PubMed database, and in 1 year the number grew to 200.737 (PubMed, Available from: http:// www.ncbi.nlm.nih.gov/pubmed, cited 2013 November 30). This means that in only 1 year there are more than 10.000 case reports published in the database. This huge number of citations shows that case reports have contributed a big proportion of medical literature and grow rapidly over time. ${ }^{2}$

This is because published case reports provide essential information for optimal patient care because they can describe important scientific observations that are missed or undetected in clinical trials, and provide individual clinical insights thus expanding our knowledge base and giving birth to new research lines. Information strays from the classical textbook case, leading to a better and safer patient care.

The reason is that the human being has many features that make it wonderful: it has a complex anatomy and physiology, communication skills, intelligence, imagination, emotion, and most surprising is the fact that each of us is unique, as a product of a harmonious genetic and environmental interaction. Doctors treat patients, not diseases. ${ }^{3}$

The act of recording, discussion with colleagues, and publishing our clinical observations with patients remains essential to the art of medicine and patient care. As Osler once said "Always note and record the unusual...Publish it. Place it on permanent record as a short, concise note. Such communications are always of value." 4

Few if any have had formal training on what constitutes a good case report and how to write one. Unlike many other aspects of our medical training, that of writing case reports is not standardized. There is a wide body of published literature on how to construct a case report, including the different sections of a case report and when to write one, but different journals have different criteria and case report quality can be variable. We made an effort trying to accomplish this by writing the book "Case Reports: Semiology and Publication" (in spanish: Casos Clínicos: Semiología y Publicación), looking for standardize the form of how to make, present at a medical congress, and even publish a case report.

There are guidelines for different publication types: randomized controlled trials (Consolidated Standards of Reporting Trials, or CONSORT), observational studies (Strengthening the Reporting of Observational studies in Epidemiology, or STROBE), and systematic reviews and meta-analyses (Preferred Reporting Items for Systematic Reviews and Meta-Analyses, or PRISMA); guidelines have also been developed for adverse-event case reports, and all authors should be familiar with the Committee on Publication Ethics (COPE) and the Enhancing the Quality and Transparency of Health Research (EQUATOR) Network. But, it was not until September 2013, that an international reporting guideline for case reports (CARE) was presented. It will provide an international, general, non-journal-specific framework for completeness and transparency for published case reports, striking a balance between adequate detail and concise writing that can be used by all authors for all journals that publish case reports. ${ }^{5}$

The CARE guidelines consists of a checklist that comprises 13 primary items to include when writing a case report: title, key words, abstract, introduction, patient information, clinical findings, timeline, diagnostic assessment, therapeutic interventions, follow-up and outcomes, discussion, patient perspective, and informed consent (CARE Guidelines, Available from: http:// www.care-statement.org/care-checklist.html, cited 2014 July 30).

Every case report is divided into five sections: abstract, introduction, case presentation, discussion and conclusion. The abstract briefly summarizes the case and its clinical relevance. It should clearly state the subject and educational value of the case report to introduce the readers to the central theme of the article. Writing the abstract is easy after the whole text is written. It is important because it gives information about

\footnotetext{
${ }^{1}$ Department of Cardiac Sugery, University Clinic Hospital of Valladolid, Valladolid, Spain.

${ }^{2}$ National Institute of Health. USA.
} 
what the article is about, and its availability will allow for easier retrieval from electronic database and help researchers discern their level of interest in the manuscript. The Introduction should be concise and immediately attract the attention and interest of the reader. It should provide the important information of the case report, background, epidemiologic data and novelty of the case report. In this section, make the case worthy to be published to the readers of the journal.

The case presentation should describe the patient's story in chronological order and in enough detail for the reader to establish his or her own conclusions about the case's validity. It should include information that pertains to the case with a clinical teaching point, and avoid confusing, irrelevant and superfluous data. The patient demographics such as age, sex and race must be included.

The discussion section is the most important section of the case report. It is the selling point that makes the article worth publishing. It should evaluate the patient's case for accuracy, validity, and uniqueness; compare and contrast the case report with the published literature; derive new knowledge; summarize the essential features of the report; and draw recommendations. The conclusion section should be brief and based on the evidence reviewed in the discussion section, and emphasize its applicability to practice. The author may suggest that clinicians be aware of the insight learned from the case or suggest heightened vigilance, prudent management, avoidance, further study before taking action, or new ideas for investigation. ${ }^{6}$

Last, the author must choose an interesting title. It is very important because many readers screen articles looking only at the title. We suggest developing the title after writing the whole text to see what have been discussed predominantly in the article.

Early case reports were anecdotal reportings about a novelty disease. However, a truly unique case is a rare event in clinical practice, and by focusing solely on novelty, many authors de-emphasize the educational value of their reports. Cases that increase the awareness of an unusual condition, describe a rare presentation of a common condition, describe diagnostic errors, their causes and consequences, rebut an accepted theory, or identify innovative treatment and diagnostic strategies are valuable additions to the medical literature whether they are novel or not.3,7
Writing case reports need academic and clinical skills, along with a sense of art to interest the editor to publish and the readers to read and study about the case we report. It is a combination between writing with academic knowledge and logical thinking, and art to interest people, or make colleagues want to know more and study about that special case report. Like any other literature is a work of art, a case report is also an art. Given the broad range of topics that can be legitimately highlighted in a case report, every one during their medical career can write a case report. It offers an excellent opportunity to gain experience in scientific writing, which will keep improving with the articles you will write. This practice of continuous writing will help you discover the skills necessary to make any manuscript you write worth publishing to any journal submitted.

It is the teaching point that makes case reports worth publishing, so every clinician and academic professional who wants to published case report must show the novelty and teaching point to the editors and readers. Every author of a case report must focus on why is the case important for the reader, why the report should be published, and who will read it. ${ }^{2}$

Writing a case report can be difficult for several clinicians or lecturers, even though they are experienced clinicians. We hope to encourage authors to write and submit manuscripts. By writing case reports, they will build their own clinical reasoning about patients and also sharpen their clinical instinct.

\section{References}

1. Rison RA. A guide to writing case reports for the Journal of Medical Case Reports and BioMed Central Research Notes. J Med Case Rep. 2013 Nov 27;7:239.

2. Pramono LA. Sciene and the Art of Case Reporting in Medicine. Acta Med Indones. 2013 Oct;45(4):324-8.

3. Ortega-Loubon C, Correa-Márquez R. Casos Clínicos. Semiología y Publicación. 1st edition. Panamá; iMedPub; 2010.

4. Thayer WS: Osler, The Teacher Sir William Osler, Bart. Baltimore: Johns Hopkins Press; 1920:51-52.

5. Rison RA, Kidd MR, Koch CA. The CARE (CAse REport) guidelines and the standardization of case reports. J Med Case Rep. 2013 Nov 27;7(1):261

6. Cohen H. How to write a case report. Am J Health Syst Pharm. 2006 Oct 1;63(19):1888-92.

7. Carleton HA, Webb ML. The Case report in context. Yale J Biol Med. 2012 Mar;85(1):93-6.

\section{Acknowledgments}

We would like to thank Francisco Javier Bonilla-Escobar, Editor in Chief of IJMS, for the invitation to write an Editorial to the Journal regarding our experience on Writing Case Report.

Conflict of Interest Statement at Funding

The Authors have no funding, financial relationships or conflicts of interest to disclose.

Author Contributions

Conception and design the work/idea: COL RCM. Write the manuscript: COL RCM. Critical revision of the manuscript: COL RCM. Approval of the final version: COL RCM.

Cite as:

Ortega-Loubon C, Correa-Marquez R. Writing a Case Report: A Work of Art. Int J Med Students. 2014 Jul-0ct;2(3):90-1. 